\title{
Premier je suis, Second je fus, Molecular Psychiatry ne change
}

\section{Molecular Psychiatry (2010) 15, 777; doi:10.1038/mp.2010.85}

When the Bordeaux Wine Official Classification of 1855 was created, four chateaus were ranked as being first tier: Lafite, Latour, Haut Brion and Margaux. Mouton was ranked as the top of the second tier. Baron Philippe de Rothschild never accepted being number 2 and spent decades fighting the rigid French bureaucracy until 1973, when Mouton was elevated to 'first growth' status. When he achieved his goal, the Baron famously stated, 'Premier je suis, Second je fus, Mouton ne change.' In English: First I am, second I was, Mouton does not change.

I am delighted to share with our readers and contributors the new classification by ISI-Thomson Reuters that now Molecular Psychiatry, with an impact factor (IF) of 15.049, is the highest-ranked journal in psychiatry (Table 1). Boldly paraphrasing the Baron, I can state that first we are, second we were, Molecular Psychiatry does not change.

When I conceptualized the journal, translational medicine did not exist as a catchy, trendy phrase, but the concept was decades old. Thankfully, my wife Ma-Li Wong, Molecular Psychiatry's Associate Editor, and I worked in the world's epicenter for that type of endeavor, the NIH Clinical Center (Building 10), where adjacent parallel corridors contained clinical wards and research labs. The fact that for 7 years we spent our days literally walking back and forth between the lab and the clinic, publishing work that translated both domains, led me to wonder in 1995 why there was not a top psychiatric journal that narrated the rapid taking off of our field from this translational perspective, publishing side by side fundamental research, clinical investigation and the healthcare implications of research, namely public health.

The terrain was very fertile but where did the seed of that idea come from? I brought the seed with me all the

Table 1

2009 Impact factor in psychiatry (117 journals)

1. Molecular Psychiatry-impact factor: 15.049

2. American Journal of Psychiatry-impact factor: 12.522

3. Archives of General Psychiatry-impact factor: 12.257

4. Biological Psychiatry-impact factor: 8.926

Molecular Psychiatry is now ranked: 1st out of 117 journals in Psychiatry

4th out of 230 journals in Neurosciences

6th out of 283 journals in Biochemistry \& Molecular Biology way from my childhood in Brazil. My older sister was a journalist, who wrote scripts for educational television, which I, at age 8, would act on Brazilian TV. It is unsettling to think that I first started working 43 years ago! Growing up with journalism around me, I went into it as a very natural thing. At age 10 I was editing and printing in a manual (and messy) stencil duplicator or mimeograph machine a newsletter for my neighborhood. Some things one does in a calculated, planned and strategic way; other things are done without any reflection, totally instinctively, naturally and organically. One has no idea why one does them. For me editing and putting a publication together is like that.

Before e-mail came about, I wrote a proposal for the journal and used the cutting edge technology of the day, the FAX machine, to send it to the publishing house in England. It was delightful to get, as a response, my own FAX back with the following brief comment from Marija Vukovojac, Macmillan Press, simply stating: 'What a wonderful idea!'

Since then we have with each issue fulfilled our editorial goal of being the ground zero for the communication of the full spectrum of translational research in psychiatry. As a result, our IF rapidly rose, from 2 to 4 to 8 , and we rapidly became the number 2 journal in the field. When we doubled our pagination, the IF naturally dropped some. But we rapidly rose up againback to number 2-which is where we have been for so many years. Was Molecular Psychiatry ever number 2? I don't think so. It is my belief that things have an intrinsic value that may not be promptly recognized in the outer world. We are exactly the same journal now that we were in 1996. The concept is the same. Re-structuring the Baron's quote: Molecular Psychiatry does not change, second we were, first we are.

The ratings are fickle. There is no guarantee that next year the Archives of General Psychiatry will not go back to the top position that it had for so many decades. What is structurally decisive and everlasting is the inner structure: in this case our unwavering commitment to being the most desirable home for translational research in psychiatry. We personally thank our readers, contributors and reviewers who worked together with us for many years to take Molecular Psychiatry from a novel concept in 1996 to number 1 in 2010.

\author{
J Licinio (Editor) \\ John Curtin School of Medical Research, \\ Australian National University, Canberra, Australia \\ E-mail: julio.licinio@anu.edu.au
}

